\title{
Does Voluntary Redundancy Affect General Practice Consultation Rates?
}

\author{
Maj J Allingham \\ MRCGP, DRCOG, RAMC \\ Regimental Medical Officer
}

Medical Centre, 1 RGBW, Alma Barracks, Catterick Garrison, North Yorks, DL9 $3 A Q$

SUMMARY: This paper presents a retrospective case control study of the General Practice consultation rates of 58 soldiers made voluntarily redundant. The redundees were compared over 140 days prior to the announcements of redundancy and 140 days after the announcements. No difference in consultation rates was found between the groups suggesting that voluntary redundancy in the Army has no effect on health and health seeking behaviour.

\section{Introduction}

Unemployment has been linked with an increased incidence of suicide, cancer, accidents, violence, depression, cardiovascular disease and many other conditions in several studies $(1,2,3,4)$. Few studies have, however, considered the effect of voluntary redundancy on health seeking behaviour. In research from a Danish Shipyard it was reported that redundancy led to a reduction in accidents and illness of the digestive system with an increase in cardiovascular disease. Furthermore threat of redundancy decreased certified sickness absence in the under 40's but in workers fearful of job loss there was more illness and absences from work were longer (1).

It would appear that the effect of voluntarily becoming redundant has not been previously reported and this study was conducted in such a group in the British Army. The results strongly suggest that planned redundancy with proper pre-redundancy education opportunities minimise or negate the morbidity and even mortality known to be associated with unplanned involuntary redundancy.

\section{Subjects and Method}

This retrospective study looked at 58 male soldiers who had applied for voluntary redundancy, matched with 58 male controls, between September 1992 and July 1993.

The subjects had a mean age of 33.6 (range 28-43), had served a mean of 15.5 years (range 11-22) in the Army, 12 were medically downgraded for a variety of injuries and conditions which restricted their ability to maintain full military fitness.

Each subject was matched with a control of similar age, length of service and military rank. All medically downgraded subjects were matched with a control of similar medical category. The control group had a mean age of 33.5 (range 27-45) and had served a mean of 15.1 years (range 8-22).

All subjects were seen for their final medical examination between 15th July 1993 and 5th August 1993. At their final medical examination the reason for seeking redundancy was asked using a simple open question (Fig 1).

Consultations in the 140 days prior to the announcement of the redundancies (8th October 1992 - 25th February 1993) and in the 140 days following this (26th February 1993 - 15th July 1993) were counted using a retrospective review of the General Practice record and compared to those of the control group.

The results were analysed using a $\mathrm{X}^{2}$ squared test with 1 degree of freedom.

\section{Results}

All subjects at final medical examination were askef the question "Why did you apply for redundancy? Answers given fell into 5 groups of response with 12 giving 2 reasons (Fig 1).

The pattern of consultation before and after the announcement of redundancies is shown below (Fig 2).

$$
\begin{aligned}
& \text { "Did it for the money" } \\
& \text { "Had enough of Army life" } \\
& \text { "Family reasons" } \\
& \text { "No prospect of promotion for medical reasons" } \\
& \text { (all were medically downgraded) } \\
& \text { "No prospect of promotion for other reasons" }
\end{aligned}
$$

Fig l.

\begin{tabular}{|lll|}
\hline & $\begin{array}{l}\text { 140 days prior to } \\
\text { the announcement }\end{array}$ & $\begin{array}{l}\mathbf{1 4 0} \text { days prior to } \\
\text { the announcement }\end{array}$ \\
\hline $\begin{array}{l}\text { Subjects } \\
(\mathrm{n}=58)\end{array}$ & $66(1.14$ per man $)$ & $46(0.79$ per man $)$ \\
$\begin{array}{l}\text { Controls } \\
(\mathrm{n}=58)\end{array}$ & $57(0.98$ per man $)$ & $50(0.86$ per man $)$ \\
\hline
\end{tabular}

Fig 2. $X^{2}=0.712$ with 1 degree of freedom.

There is no significant difference.

Discussion
The long term effects of job loss on health are well
described in several studies which demonstrate the
increased mortality and morbidity in association with
unemployment $(1,2,3,4,5)$. Elsewhere the threat of
redundancy has been shown to increase the frequency and
duration of sickness $(6)$.


It might be expected that the subjects of this study would show an increase in General Practice consultations due to the stress associated with uncertainty whilst waiting to see if they had been accepted for redundancy or in the following period whilst they sought employment and accommodation in civilian life. The lack of any statistical significance between consultations before and after the announcement of the redundancies suggests that volunteering to lose one's job carried no immediate adverse effect on health. This may be because leaving the Army is relatively stress free as all redundees had 8 months notice before they ceased to be paid, a good redundancy award and well organised re-settlement training to ease the transition to civilian life. It is probably true to say that being optimistic about one's future employment prospects would be associated with 'good health' with the converse true of those who were pessimistic about their future employment prospects. The resettlement education appears to instil an optimism in most of the subjects which was noted subjectively at the final medical interviews.

The group studied are young when compared with those studied elsewhere and thus may have less ill health, better prospects for employment and this could contribute to their optimistic view of the future. This would need further follow up in civilian life to assess what effect the change of employment or change to unemployment had on health and whether this optimism was justified. Unfortunately the geographical dispersal of the subjects would make this difficult.

It is interesting that only 8 subjects stated that their application for voluntary redundancy was financially motivated. The majority had either 'had enough of the army', had family reasons or had reached what they considered to be their promotional ceiling. The group was self selected as happy to leave the Army which would also contribute to a sense of optimism and hence be perceived health.

Although this is a small study of young men i 3 specific employment group it does demonstrate $\frac{a}{2} n$ apparent lack of adverse effect on health whon redundancy is voluntary. It is worth considering wh planning health care in an occupational setting where losses are threatened that volunteers will fare better then compulsory redundees and if so should need less heath resources.

\section{REFERENCES}

1. Moser KA, Fox AJ, Jones DR, Goldblatt $\frac{8}{\infty}$. Unemployment and mortality: further evidence from the OPCS longitudinal study 1971-81. Lancet 1986; i: $365-6$.

2. Moser KA, Fox AJ, Jones DR, Goldblatt Unemployment and mortality: comparison of 1971 and 1981 longitudinal study census samplegs. Br Med J 1987; 294: 84-90.

3. Melville DI, Hope D, Bennison D, Barraclou $\vec{G}$ B. Depression among men made involuntary red国dant. Psychol Med 1985; 15 (4): 789-93.

4. Crombie IK, Kenicer MB, SMith WC, Tuns PEDOE HD. Unemployment, socioenvironmental fac-

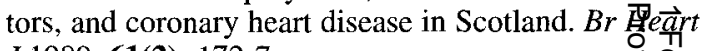
$J$ 1989; 61(2): 172-7.

5. Iversen L, Sabroe S, Damsgaard MT. Hoge tal admissions before and after shipyard closure. $B P A P^{2} d$ J 1989; 299: 1073-6.

6. Beale N, Nethercott S. Job loss and family bidity: a study of factory closure. JR Coll Gen Paxt 1985; 280: 200-2.

7. BEAle N, Nethercott S. The nature of unempleyment morbidity 2. Description. J R Coll Gen Pregrt 1988; 38: 3904. 